\title{
Deworming of stray dogs and wild canines with praziquantel-laced baits delivered by an unmanned aerial vehicle in areas highly endemic for echinococcosis in China
}

Qing $Y u^{1,2,3^{*}}$, Ning Xiao ${ }^{1,2,3+}$, Shi-jie Yang ${ }^{1,2,3+}$ and Shuai $\operatorname{Han}^{1,2,3+}$

\begin{abstract}
Background: Canines, the definitive hosts for the parasites causing alveolar (AE) and cystic echinococcosis (CE), are the main source of this infections playing the key role in the transmission. The ten-year mortality rate of AE is extremely high (94\%) if the patients are not given sustained treatment. The aim of this field study is to explore the possibility of delivery of praziquantel-laced baits using unmanned aerial vehicles (UAVs) aimed at deworming wild canines in the endemic areas.
\end{abstract}

Methods: UAVs were compared to manual bait delivery in the $1-\mathrm{km}^{2}$ test areas followed by testing of canine faeces using an Echinococcus coproantigen ELISA test in the ensuing year. The outcomes of the two approaches were compared with respect to time of delivery and overall cost.

Findings: Compared to manual bait delivery, delivery by UAVs saved up to $67 \%$ of the overall cost. Three times more staff was needed for the former approach compared to the latter and, time wise, UAV bait delivery saved $350 \%$ compared to manual bait delivery on average. With regard to investment needed, the use of UAVs showed an efficiency 2.5 times better than manual bait delivery. Compared to the area served by UAVs, the average positive rate for the canine faecal samples was more than $38 \%$ higher in the area served manually.

Conclusion: The technique of bait delivery with praziquantel using UAVs for canine deworming has a strong potential with regard to savings of manpower, time and overall cost in areas highly endemic for echinococcosis.

Keywords: Echinococcosis, Wild canine definitive hosts, Control: Unmanned aerial vehicle, Delivery, Baits, Qinghai-Tibet Plateau, China

\footnotetext{
* Correspondence: yuqing@nipd.chinacdc.cn

†Equal contributors

'Department of Echinococcosis, National Institute of Parasitic Diseases,

Chinese Center for Disease Control and Prevention, 207 Rui Jin Er Road,

Shanghai 200025, China

${ }^{2}$ Key Laboratory of Parasite and Vector Biology, National health and Family

Planning Commission, Shanghai, China

Full list of author information is available at the end of the article
} 


\section{Multilingual abstracts}

Please see Additional file 1 for translations of the abstract into the six official working languages of the United Nations.

\section{Background}

Cystic echinococcosis (CE), due to Echinococcus granulosus, and alveolar echinococcosis (AE), due to E. multilocularis, are caused by the larval cystic stage of these small tapeworms. Canines are the most common definitive hosts with herbivorous animals, such as sheep, cattle and goats as intermediate hosts. Humans are infected accidentally and do not transmit the infection further. Still, more than one million persons suffer from echinococcosis globally [1]. Due to the high disease burden and mortality (up to $94 \%$ within ten years if sustained treatment is not provided) of $\mathrm{AE}$, this form of the disease has been called "the worm tumour" [1-4].

Echinococcosis (also called hydatid disease) is widely distributed in the pastoral and agriculture-pastoral parts of China, including the provinces and autonomous regions of Inner Mongolia, Sichuan, Yunnan, Tibet, Shaanxi, Gansu, Qinghai, Ningxia, and Xinjiang where canines constitute the main source of infection. A national epidemiological survey in China carried out in 2012 showed an average prevalence rate of this infection in dogs of $4.3 \%$ by a coproantigen ELISA test, whereas it reached $70 \%$ prevalence among stray/wild dogs in parts of Yushu Tibetan Autonomous Prefecture of Qinghai Province [5-8]. Baits laced with praziquantel (PZQ) for control of the adult form of E. granulosus in wild canids have been used effectively in areas endemic for $\mathrm{AE}$ in Europe [9-11]. Measures based on monthly dog treatment, executed by the control programme in western China since 2006, produced good results, both for CE and AE control $[12,13]$. This approach showed that anthelmintic monthly PZQ treatment for dogs could eliminate disease transmission simply due to the fact that the interval between treatments is then shorter than the time required for the maturation and start of egg laying (45 days) of the parasites E. multilocularis and E. granulosus $[14,15]$. However, human $\mathrm{CE}$ and $\mathrm{AE}$ are still highly endemic in China with $\mathrm{AE}$ patients accounting for $22.4 \%$ of the total number of patients according to the latest national survey [4].

The parasites are multiple-host pathogens with passage between humans and livestock as a part of its natural circulation. This situation is exacerbated by the fact that humans commonly keep many different domestic animals, which are part of the parasite life cycle together with tame and wild canines. Wild canines in particular play a crucial role as definitive hosts in $\mathrm{AE}$ transmission characterised by wide distribution, large numbers and complex classification. To date, unavailable and/or inefficient interventions make it difficult to block the transmission in strongly endemic areas [16-20].

In China, echinococcosis is mainly co-endemic in the western region, particularly on the Qinghai-Tibet Plateau, where incidence and the number of people at risk rank one of the highest in the world (9). Furthermore, this disease threatens local farmers and herdsmen and is widely spread throughout the Shiqu County of Ganzi Tibetan Autonomous Prefecture in Sichuan Province, where both CE and AE are a severe public health concern with control considered extremely difficult, of $\mathrm{AE}$ in particular, due to the wild canine population $[4,21,22]$.

Satellite-based remote-sensing and aerial photography would be useful in finding biotopes suitable for Echinococcus transmission. The introduction of drone photography could be significantly useful here as it does not only reach inaccessible areas, but also reduces time and cost of data acquisition. Unmanned aerial vehicles (UAVs) are lightweight, have a diminutive size and can easily be efficiently manoeuvred over specified ranges, both small and large. They have been extensively applied for reconnaissance and inspections (railways, bridges, and roads) and also used to support agriculture and investigate environmental pollution and health in general [23-26]. Apart from discussions on the advantages and disadvantages of UAVS applications vis-à-vis remote-sensing for the collection of spatial, epidemiological data, there are not many studies focused on specific infectious diseases [27, 28].

Here, we explore the use of UAVs for the distribution of baits laced with PZQ for blocking CE and AE transmission by deworming wild canine populations in a highly endemic area of echinococcosis in the QinghaiTibet Plateau.

\section{Methods}

The present work took place under the auspices of the National Institute of Parasitic Diseases (NIPD), Chinese Center for Disease Control and Prevention (China CDC) as a trial in an area highly endemic for echinococcosis. A study area endemic for echinococcosis was chosen in GeMeng Town, Shiqu County in the Ganzi Tibetan Autonomous Prefecture in Sichuan.

\section{Study area}

Two pilot areas located at an average altitude of $4300 \mathrm{~m}$ in GeMeng Town, Shiqu County where wild canines (stray dogs, foxes, and wolves) roam free in close contact with livestock was recommended by local residents. One area was used for manual bait delivery and the other for UAV delivery. A mobile global positioning system (GPS) device (Model: 
GPSMAP 629SC) was used to locate and synchronize the point for bait distribution.

The total coverage was $0.48 \mathrm{~km}^{2}$ divided into $0.24 \mathrm{~km}^{2}$ for each area, which in turn were divided into units of 20 (latitudinal distance) $\times 100$ (longitudinal distance) meters containing fixed points for bait delivery. The baits were distributed in every cross point by $20 \times 100 \mathrm{~m}$ meaning that a total of 240 fixed points were set up and recorded by the GPS instrument (Figs. 1 and 2).

\section{Study design}

Beads with a diameter of $13 \mathrm{~mm}$ containing an effective dose of $50 \mathrm{mg}$ PZQ (Nanjing Pharmaceutical Co., Ltd., Jiangsu Province, China) were used as bait. As tame dogs are normally dewormed with an effective dose of 200-400 mg PZQ depending on weight, we used eight beads as bait (400 $\mathrm{mg}$ PZQ in total) in each place.

The baits were distributed manually in one of the two study areas and by an UAV in the other. The UAV (model 4DE1000) was rented from an independent company (Jiangsu AI Jin agrochemical Co., Ltd., Jiangsu Province, China) and modified by them for the bait dosage delivery. The UAV had multi-rotors giving the device a flight radius of $200 \mathrm{~m}$ with a load up to $5 \mathrm{~kg}$. Other characteristics included a $3-5 \mathrm{~m} / \mathrm{s}$ climb rate, 20 $36 \mathrm{~km} / \mathrm{h}$ flight speed, 4-5 grade speed wind resistance and 20 min flight time.

Faecal samples were collected at the same places where the baits were delivered in both study areas every 2 months in 2016 from April to October. The type of animal that had produced the faecal samples was identified
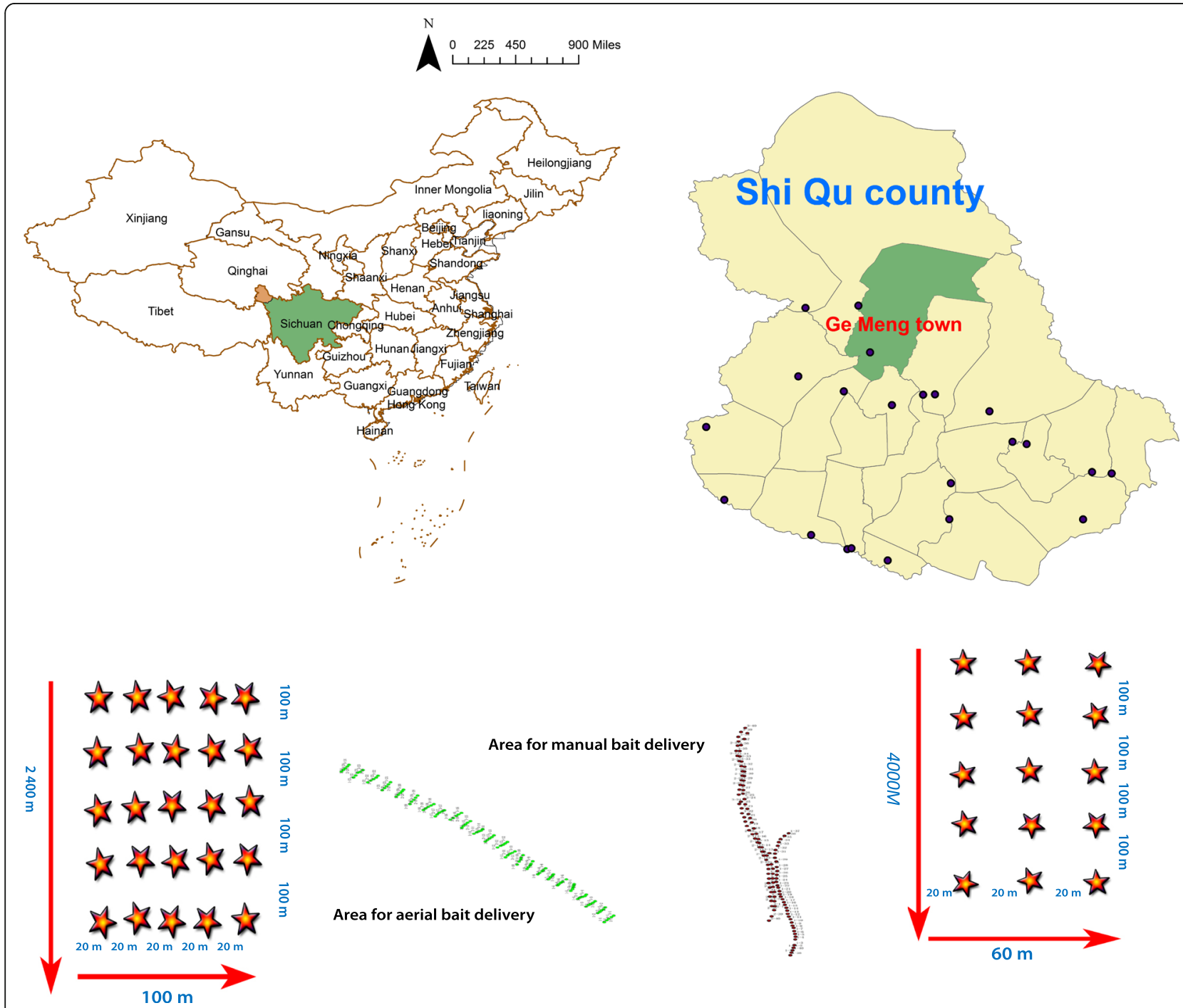

Fig. 1 Area distribution for aerial and manual bait delivery. The bait was distributed in every $20 \times 100 \mathrm{~m}$ cross point over the total coverage area of $0.48 \mathrm{~km}^{2}$ with $0.24 \mathrm{~km}^{2}$ for each area 


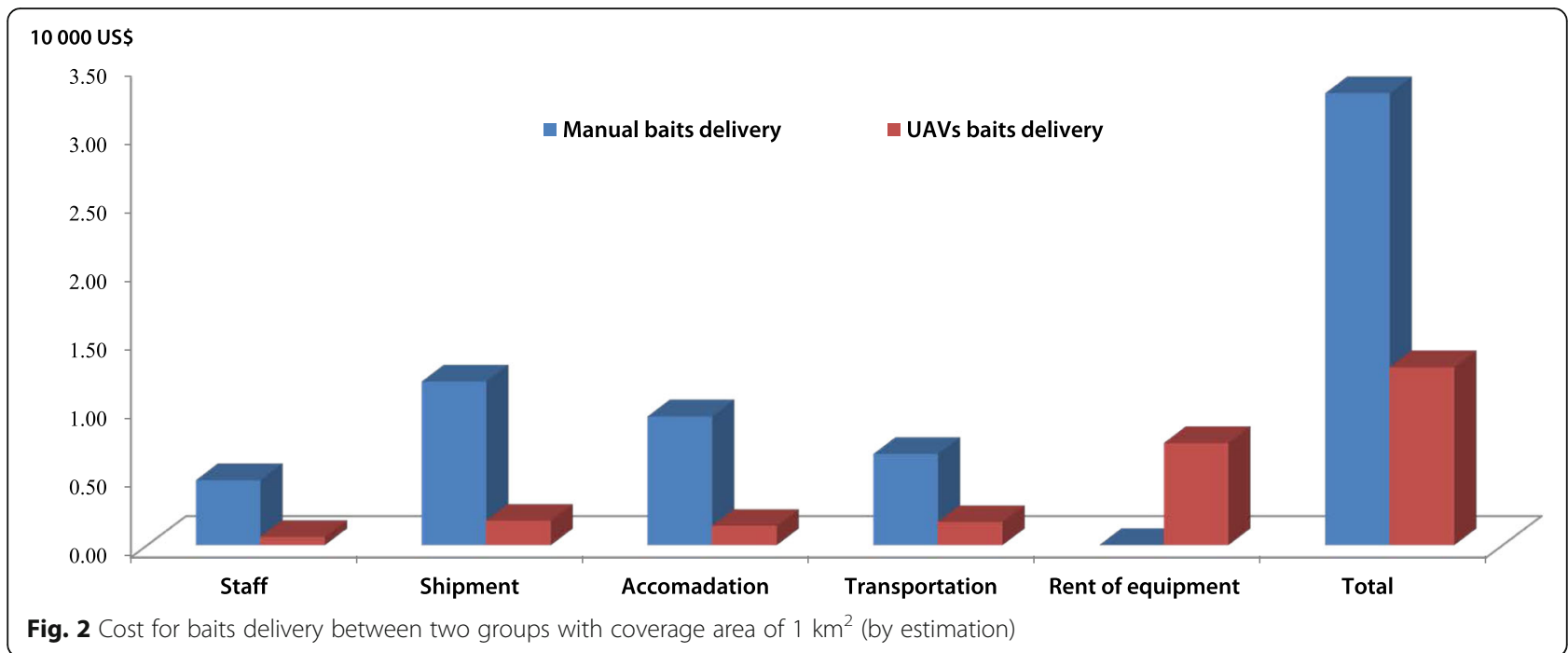

with the aid of local residents and tested for Echinococcus antigen using a commercially available coproantigen ELISA test (Shenzhen Combined Biotech Co., Ltd., Guangdong Province, China.).

\section{Statistics and records}

Maps covering the study area were produced using ArcGIS software version 10 (ESRI, Redlands, CA, USA). Fisher's exact test was used for the statistical analysis that was performed using Microsoft Excel software version 2010 and SPSS Statistics v18.0 (Statistical Package for the Social Sciences. SPSS Institute, Chicago, IL, USA). A statistically significant difference was defined as a $P$-value $<0.05$.

During the whole process, labour and time for bait delivery and costs for staff, transportation, UAV rent and fuel, were recorded, statistically analyzed and calculated using the exchange rate of 6.5 RMB Yuan per USD.

\section{Results}

\section{Labour and time consumption}

In the study area where the UAV was used, two staff spending $60 \mathrm{~min}$ (recorded by stopwatch) was needed for the task, while six staff working for $270 \mathrm{~min}$ had to be hired for the manual operation in the other area. Thus, only a third of the manpower rate for manual delivery was needed for UAV delivery. In addition, the latter approach saved 350\% [(270-60)/60] of the time compared to manual bait delivery.

\section{Cost of baits delivery}

Comparing the cost between the two groups for bait delivery over the one $\mathrm{km}^{2}$ area (equal to one million $\mathrm{m}^{2}$ ), the results showed that the expenditure was 3.29 USD/ $100 \mathrm{~m}^{2}$ in the manual area against $1.30 \mathrm{USD} / 100 \mathrm{~m}^{2}$ using UAV delivery. Thus, the use of UAVs saved approximately $60.5 \%[(3.29-1.30) / 3.29]$ of the financial expenditure, i.e. the final cost was more than 2.5 times better with UAV delivery (Table 1).

\section{Deworming outcome}

A total of 464 faecal samples were collected from the 240 fixed points in the two study areas. No significant difference between two areas was found $\left(\chi^{2}=0.09\right.$, $P>0.05)$. However, it was noted that the life cycle of $E$. granulosus included mainly a dog-sheep-dog cycle but goats, swine, horses, cattle, camels, yaks and other domestic animals were also involved, while that of $E$. multilocularis also involved foxes, other carnivores and small mammals (mostly rodents). In both our study areas, the number of faecal samples of foxes found ranked at the top followed by stray dogs with wolves in the third place. Moreover, the average infection rate based on the coproantigen ELISA was $38.2 \%[(1.52-1.10) / 1.10]$ higher in the manual area than in the one served by the UAVs, likely attributed to the different probability for baits uptake by wild canids in manual and UAV areas, as well as, to the uneven density of small mammals whose populations fluctuate tremendously (Table 2).

Table 1 Cost of baits delivered manually vis-à-vis unmanned aircraft vehicle delivery

\begin{tabular}{llllllll}
\hline Type of bait delivery & Area $\left(\mathrm{m}^{2}\right)$ & Staff & Ship-ment & Accommo-dation & Transpor-tation & Rent of equipment & Total $\left(\right.$ USD $\left.\times 10^{4}\right)$ \\
\hline UAV $^{a}$ & $10^{6}$ & 0.06 & 0.18 & 0.14 & 0.17 & 0.75 & 1.30 \\
Manual & $10^{6}$ & 0.48 & 1.20 & 0.94 & 0.67 & 0.00 & 3.29 \\
\hline
\end{tabular}

anmanned aircraft vehicle 
Table 2 Test results for Echinococcus antigen in faecal samples after praziquantel-laced baits delivered manually vis-à-vis unmanned aircraft vehicle delivery

\begin{tabular}{|c|c|c|c|c|c|c|}
\hline \multirow[t]{2}{*}{ Type of bait delivery } & \multirow{2}{*}{$\begin{array}{l}\text { Time of faecal } \\
\text { collection }\end{array}$} & \multirow{2}{*}{$\begin{array}{l}\text { Number of } \\
\text { samples }\end{array}$} & \multicolumn{3}{|c|}{ Proportion of faeces from wild animals (\%) } & \multirow{2}{*}{$\begin{array}{l}\text { Positive rate }{ }^{\mathrm{b}} \\
\%\end{array}$} \\
\hline & & & Stray dogs & Foxes & Wolves & \\
\hline \multirow[t]{4}{*}{ Unmanned aircraft vehicle (UAV) } & April & 60 & 20.83 & 25.00 & 54.17 & 1.67 \\
\hline & June & 55 & 55.17 & 37.93 & 6.90 & 1.82 \\
\hline & August & 66 & 14.71 & 64.71 & 20.59 & 0.00 \\
\hline & October & 36 & 0.00 & 89.47 & 10.53 & 0.00 \\
\hline Total & & 217 & 24.53 & 52.83 & 22.64 & 1.10 \\
\hline \multirow[t]{4}{*}{ Manual } & April & 75 & 56.90 & 36.21 & 6.90 & 1.33 \\
\hline & June & 73 & 36.00 & 56.00 & 8.00 & 1.37 \\
\hline & August & 50 & 2.86 & 77.14 & 20.00 & 2.00 \\
\hline & October & 49 & 41.18 & 41.18 & 17.65 & 0.00 \\
\hline Total & & 247 & 37.04 & 51.11 & 11.85 & 1.52 \\
\hline Grand total & & 464 & 31.19 & 51.92 & 16.90 & 1.08 \\
\hline
\end{tabular}

Identified by shape; ${ }^{\mathrm{b} C o p r o a n t i g e n ~ E L I S A ~ t e s t ~}$

\section{Discussion}

As far as we are aware this is the first study of the use of UAVs for the distribution of praziquantel-laced baits for the control of echinococcosis. Our results show that considerable costs, as well as time, can be saved by this approach.

The type of animals found to play the role of definite hosts in $\mathrm{CE}$ and $\mathrm{AE}$ transmission were those mentioned in other reports $[9,28]$. Though prevention and control of $\mathrm{AE}$ is particularly complex since the parasite's life cycle involves wild animal species as both definitive and intermediate hosts, distribution of anthelmintic baits against wild and stray definitive hosts results in significant reductions in $\mathrm{AE}$ prevalence. For example, the risk for $\mathrm{AE}$ in Germany has been pointed out $[10,11]$ with a field study in southern Germany indicating reduced $E$. multilocularis prevalence in red foxes after anthelmintic bait delivery [29]. In northern Japan, a baitdelivered anthelmintic also reduced the prevalence of this parasite in red foxes putting forward a discussion of optimizing anthelmintic ways in a more costeffective manner [30-32]. As it is already clear that treatment of animals is a successful approach for echinococcosis control, with special reference to wild carnivores in the case of $\mathrm{AE}$, the main focus of our study was to evaluate a new cost-effective technique for the anthelmintic bait delivery.

The finding that foxes and stray dogs rank at the top in terms of faecal matter found in the field indicate that canids have wide distribution in rural environments though we need more proof to confirm this by further research on wild canine activities, including observation and genetic detection of the faecal samples. Another limitation of this study was the short duration of observation that made it difficult to show the long-term positive effect of canid deworming beyond doubt. Still, it is already obvious that deworming wild and tame canids through PZQ-laced baits delivered by UAVs saves both cost and labour.

\section{Conclusion}

The technique of baits with praziquantel delivery using UAVs for canine deworming has the potential to save cost and labour in areas highly endemic for echinococcosis. This has been shown to be true in Qinghai-Tibet Plateau and should work equally well also in other areas.

\section{Additional files}

Additional file 1: Multilingual abstracts in the six official working languages of the United Nations. (PDF 633 kb)

Additional file 2: Baits delivery by UAVs. (MP4 74,029 kb)

\section{Abbreviation}

UAVs: Umanned aircraft vehicles

\section{Acknowledgements}

We are very appreciated at Dr. Robert Bergquist for his comments and suggestions which help to improve the presentation of the paper, as well as, we also thank all those participants for their contribution of time and patience in the study.

\section{Funding}

This fields study was supported by the project of Ganzi Tibetan Autonomous Prefecture station for echinococcosis control, China CDC.

Availability of data and materials Additional file 2

Authors' contributions

QY and NX was the principal writer of the proposals and QY designed the protocol of investigation and evaluation. JSY and SH coordinated the fields survey and data record. All authors read and approved the final manuscript. 


\section{Ethics approval and consent to participate}

The study does not involve the use of any animal or human samples.

\section{Consent for publication}

Agreement for publication.

\section{Competing interests}

The authors declare that they have no competing interests.

\section{Author details}

${ }^{1}$ Department of Echinococcosis, National Institute of Parasitic Diseases, Chinese Center for Disease Control and Prevention, 207 Rui Jin Er Road, Shanghai 200025, China. ${ }^{2}$ Key Laboratory of Parasite and Vector Biology, National health and Family Planning Commission, Shanghai, China. ${ }^{3} \mathrm{WHO}$ Collaborating Center for Tropical Diseases, Shanghai, China.

Received: 17 January 2017 Accepted: 19 June 2017

Published online: 27 June 2017

\section{References}

1. McManus DP, Zhang W, Li J, Bartley PB. Echinococcosis. Lancet. 2003;362: 1295-304.

2. Torgerson PR, Keller K, Magnotta M, Ragland N. The global burden of alveolar echinococcosis. PLoS Negl Trop Dis. 2010:4(6):e722.

3. Cadavid Restrepo AM, Yang YR, McManus DP, Gray DJ, Giraudoux P, Barnes TS, et al. The landscape epidemiology of echinococcoses. Infect Dis Poverty. 2016:5:13. doi:10.1186/s40249-016-0109-x.

4. Bhutta ZA, Sommerfeld J, Lassi ZS, Salam RA, Das JK. Global burden, distribution, and interventions for infectious diseases of poverty. Infect Dis Poverty. 2014;3:21. doi:10.1186/2049-9957-3-21.

5. Wang GQ. Epidemiological survey on echincoccosis in China. Shanghai: Shanghai Science and Technology Press; 2016. (in Chinese)

6. Ma J, Wang H, Lin G, Zhao F, Li C, Zhang T, et al. Veterinary parasitology surveillance of echinococcus isolates from Qinghai, China. Vet Parasitol. 2015:207(1-2):44-8. doi:10.1016/j.vetpar.2014.11.012.

7. Wang $Q$, Huang $Y$, Huang $L, Y u$ W, He W, Zhong B, et al. Review of risk factors for human echinococcosis prevalence on the Qinghai-Tibet plateau, China: a prospective for control options. Infect Dis Poverty. 2014;3:3. doi:10. 1186/2049-9957-3-3.

8. Budke CM, Campos-Ponce M, Qian W, Torgerson PR. A canine purgation study and risk factor analysis for echinococcosis in a high endemic region of the Tibetan plateau. Vet Parasitol. 2005:127:4349.

9. World Health Organization. Report of the WHO informal working group on cystic and alveolar echinococcosis surveillance, prevention and control with the participation of the food and agriculture Organization of the United Nations and the world organisation for animal health. Geneva: World Health Organization; 2011. Ref: WHO/HTM/ NTD/NZD/2011.2 or ISBN 9789241502924

10. Ecket J, Deplazes P. Alveolar echinococcosis in humans: the current situation in central Europe and the need for countermeasures. Parasitol Today. 1999;15:315-9.

11. Eckert J, Conraths FJ, Tackmann K. Echinococcosis: an emerging or reemerging zoonosis? Int J Parasitol. 2000;30:1283-94.

12. Zhang W, Zhang Z, Wu W, Shi B, Li J, Zhou X, et al. Epidemiology and control of echinococcosis in central Asia, with particular reference to the People's Republic of China. Acta Trop. 2015;141:235-43. doi:10.1016/j. actatropica.2014.03.014

13. Xiao N, Yao JW, Ding W, Giraudoux P, Craig PS, Ito A. Priorities for research and control of cestode zoonoses in Asia. Infect Dis Poverty. 2013;2:16. doi: 10.1186/2049-9957-2-16

14. Moro P, Schantz PM. Echinococcosis : a review. Int J Infect Dis. 2009;13(2): 125-33. doi:10.1016/j.jijid.2008.03.037.

15. Wang Q, Yu WJ, Zhong B, Shang JY, Huang L, Mastin A, et al. Seasonal pattern of Echinococcus re-infection in owned dogs in Tibetan communities of Sichuan, China and its implications for control. Infect Dis Poverty. 2016;5:60. doi:10.1186/s40249-016-0155-4.

16. Kachani M, Heath D. Dog population management for the control of human echinococcosis. Acta Trop. 2014;139:99-108.

17. Craig PS. Epidemiology of human alveolar echinococcosis in China. Parasito Int. 2006;55:S221-5.
18. Kapel CMO, Torgerson PR, Thompson RCA, Deplazes P. Reproductive potential of echinococcus multilocularis in experimentally infected foxeses, dogs, raccoon dogs and cats. Int J Parasitol. 2006;36:79-86.

19. Tambo E, Khater El, Chen JH, Bergquist R, Zhou XN. Nobel prize for the artemisinin and ivermectin discoveries: a great boost towards elimination of the global infectious diseases of poverty. Infect Dis Poverty. 2015:4:58. doi:10.1186/s40249-015-0091-8.

20. Zhou XN. Prioritizing research for "One health - One world". Infect Dis Poverty. 2012;1:1. doi:10.1186/2049-9957-1-1.

21. Budke CM, Jiamin Q, Qian W, Torgerson PR. Economic effects of echinococcosis in a disease-endemic region of the Tibetan plateau. Am J Trop Med Hyg. 2005;73:210.

22. Tiaoying L, Jiamin Q, Wen Y, Craig PS, Xingwang C, et al. Echinococcosis in Tibetan populations, western Sichuan province, China. Emerg Infect Dis. 2005;11:1866.

23. Mathe K, Busoniu L. Vision and control for UAVs: a survey of general methods and of inexpensive platforms for infrastructure inspection. Sensors (Basel). 2015;15(7):14887-916.

24. Zhang C, Walters D, Kovacs JM. Applications of low altitude remote sensing in agriculture upon farmers' requests-a case study in north-eastern Ontario, Canada. PLoS One. 2014;9(11):e112894.

25. Capolupo A, Pindozzi S, Okello C, Boccia L. Indirect field technology for detecting areas object of illegal spills harmful to human health: application of drones, photogrammetry and hydrological models. Geospat Health. 2014 8(3):S699-707.

26. Fornace KM, Drakeley CJ, William T, Espino F, Cox J. Mapping infectious disease landscapes: unmanned aerial vehicles and epidemiology. Trends Parasitol. 2014;30(11):514-9.

27. Charlier J, Bennema SC, Caron Y, Counotte M, Ducheyne E, Hendrickx G, et al. Towards assessing fine-scale indicators for the spatial transmission risk of Fasciola hepatica in cattle. Geospat Health. 2011:5(2):239-45.

28. Eckert J, Deplazes P. Biological, epidemiological and clinical aspects of echinococcosis: a zoonosis of increasing concern. Clin Microbiol Rev. 2004 17(1):107-35.

29. Schelling U, Frank W, Will R, Romig T, Lusicus R. Chemotherapy with praziquantel has the potential to reduce the prevalence of Echinococcus multilocularis in wild foxes (Vulpes vulpes). Ann Trop Med Parasitol. 1997; 91(2):179-86.

30. Morishima Y, Tsukada H, Nonaka N, Oku Y, Kamiya M. Coproantigen survey for Echinococcus multilocularis prevalence of red foxes in Hokkaido. Jpn Parasitol Int. 1999:48(2):121-34

31. Morishima Y, Tsukada H, Nonaka N, Oku Y, Kamiya M. Evaluation of coproantigen diagnosis for natural Echinococcus multilocularis infection in red foxes. Jpn J Vet Res. 1999:46(4):185-9.

32. Tsukada H, Morishima Y, Nonaka N, Oku Y, Kamiya M. Preliminary study of the role of red foxes in Echinococcus multilocularis transmission in the urban area of Sapporo, Japan. Parasitol. 2000;120(Pt 4):423-8.

\section{Submit your next manuscript to BioMed Central and we will help you at every step:}

- We accept pre-submission inquiries

- Our selector tool helps you to find the most relevant journal

- We provide round the clock customer support

- Convenient online submission

- Thorough peer review

- Inclusion in PubMed and all major indexing services

- Maximum visibility for your research

Submit your manuscript at www.biomedcentral.com/submit
Biomed Central 